\title{
Pneumothorax/Pneumomediastinum/Pneumoperitoneum: A Very Rare Complication of ERCP
}

\author{
Muddasir Ashrafa, b
}

\begin{abstract}
We present a 26-year-old Indian female who presented to the hospital with symptoms of right upper quadrant abdominal pain. Workup was suggestive of cholelithiasis and choledocholithiasis. Patient underwent urgent endoscopic retrograde cholangiopancreatography (ERCP) with sphincterotomy and had successful removal of a stone along with stent placement. Patient developed post-operative back pain and chest pain. Workup revealed retroperitoneal air, pneumoperitoneum, pneumomediastinum and right sided pneumothorax; gastrointestinal series (UGI) gastrograffin study was negative for any leak. Patient underwent chest tube placement which resolved the pneumothorax. Pt improved with non-operative management and did not require any surgical intervention for retroperitoneal duodenal perforation. This is a very rare complication of ERCP described in literature in some case reports and needs to always be considered as missing such complications can have significant morbidity/mortality.
\end{abstract}

Keywords: Pneumothorax; ERCP; Complication

\section{Introduction}

Endoscopic retrograde cholangiopancreatography (ERCP) is a common procedure used to treat biliary and pancreatic disorders, but it is a relatively complex endoscopic procedure since it requires specialized equipment and has a long learning curve to develop proficiency. Its benefits in the minimally invasive management of biliary and pancreatic disorders are challenged by a higher potential for serious complications than any other standard endoscopic technique. Pancreatitis is the most common complication, but there are other rare complications that should be recognized early to prevent serious morbidity and mortality in these patients.

\section{Case Report}

We present a 26-year-old female who presented to the hospi-

Manuscript submitted April 25, 2018, accepted May 10, 2018

aTrinity Medical Center, Rock Island, IL 61201, USA

${ }^{\mathrm{b} C}$ Corresponding Author: Muddasir Ashraf, Trinity Medical Center, Rock Island, IL 61201, USA. Email: muddasirashraf@hotmail.com

doi: https://doi.org/10.14740/jmc3070w tal with the symptoms of right upper quadrant abdominal pain. Her pain started 1 day prior to arrival in emergency room (ER). Patient went to urgent care and had abdominal ultrasound done which showed cholelithiasis, choledocholithiasis and mildly dilated common bile duct. Labs were significant for elevated ALT 1770, AST 1485, ALP 231 and TB 2.3. Patient was taken for urgent ERCP and underwent stone removal with stent placement. Patient did have some brisk bleeding at sphincterotomy site, which was controlled by injecting epinephrine and hemoclips. Patient subsequently had post-operative back pain and chest pain. CT abdomen and chest was obtained which showed right sided pneumothorax (Fig. 1), pneumoperitoneum (Fig. 2), retroperitoneal air (Fig. 2) and pneumomediastinum (Fig. 3).

General surgery was consulted, and patient underwent urgent chest tube placement which resolved the pneumothorax. Gastrointestinal series (UGI) contrast study did not show any contrast leak so patient was not taken for any emergent surgery and improved with non-operative management which included bowl rest, intravenous fluids and antibiotics. Patient later underwent laparoscopic cholecystectomy. Patient was finally discharged back home in stable condition.

\section{Discussion}

Common complications of ERCP include pancreatitis, bleed-

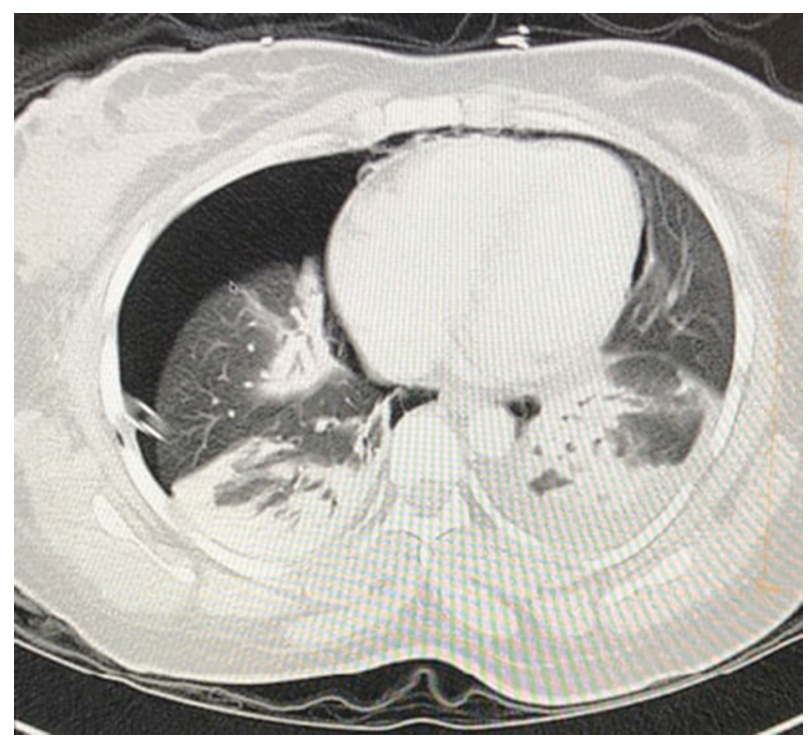

Figure 1. Pneumothorax after ERCP on CT imaging. 


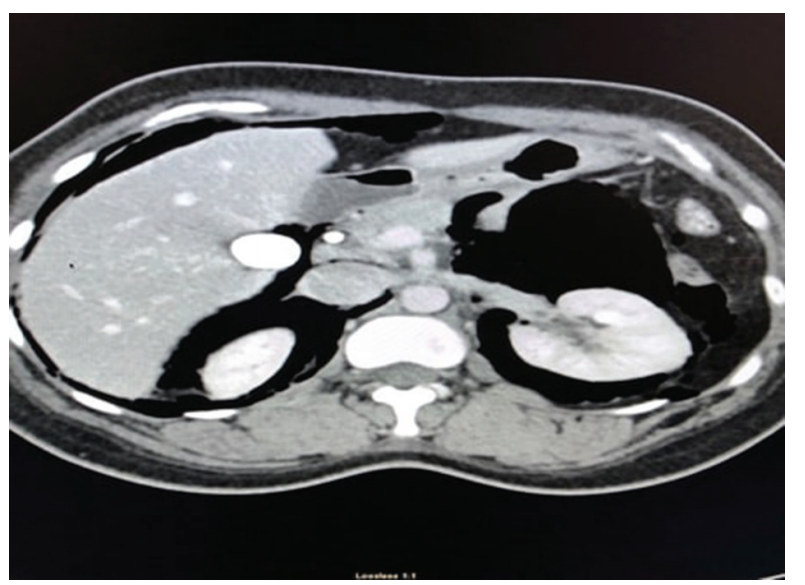

Figure 2. Pneumoperitoneum and retroperitoneal air on CT abdomen.

ing, cholangitis and duodenal perforation. Pneumoperitoneum, pneumomediastinum and pneumothorax are very rare complications and there are only few case reports in literature; thus, they are needed to be reported to know the true incidence of such events [1-3]. Our patient most likely had retroperitoneal duodenal perforation, but there was no radiological evidence of active leak on UGI contrast study, but it does not rule out perforation. The most common risk factors for retroperitoneal duodenal perforation are excessive sphincterotomy and bleeding at the time of ERCP which was the case with our patient. General surgery was consulted, and it was decided to manage the patient conservatively with nonoperative management which included bowl rest, intravenous fluids and antibiotics. She recovered completely and had no pain at discharge. If patients do not respond to conservative management, surgery may be needed, so close clinical monitoring is essential. The pneumomediastinum and pneumothorax likely develop due to extension of the retroperitoneal air. The exact pathophysiology behind development of pneumothorax is unknown, but it has been thought to develop possibly due to access of mediastinal air into the pleural space due to rupture of parietal pleura. It is also believed that an anatomic continuum exists between the retroperitoneum, pneumoperitoneum, mediastinum, pneumothorax and subcutaneous tissues as has been seen in many cases before. As a result, ectopic air in one of these compartments can extend to distant communicating spaces [4].

The prognosis of patients with a perforation depends upon the rapidity with which it is recognized, the clinical setting and patient comorbidities. The overall mortality was $16 \%$ in an older report that summarized the outcomes of 153 perforations following endoscopic sphincterotomy [5]. Overall mortality was $6 \%$ (seven out of 115 patients) in five large series between 1987 and 2004 [6-10] and a mortality rate of 8\% (20 out of 251 patients) was demonstrated in a review that considered major studies from the year 2000 onwards [11]. Overall mortalities of $13 \%$ (four deaths out of 30 cases) and a post-operative mortality of $27 \%$ (four deaths out of 15 cases) were reported in a retrospective study from Italy between 1999 and 2011 [12]. The overall need for surgery after perforation was approximately $38 \%$ and the mortality was approximately $7 \%$, according to

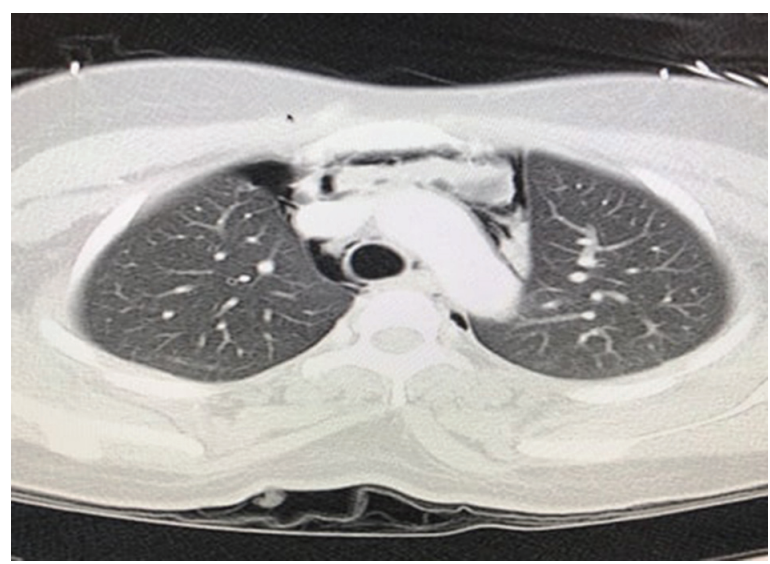

Figure 3. Pneumomediastinum on CT imaging.

results from 28 studies. The lower mortality seen in many of the more recent studies may reflect the benefits related to a conservative team approach for the management of small retroperitoneal perforations.

\section{Conclusions}

Patients with ERCP can present with very rare complications like pneumoperitoneum, pneumomediastinum and pneumothorax. It is very important to recognize these complications early to prevent serious morbidity and mortality.

\section{Conflict of Interest}

No conflict of interest exists.

\section{References}

1. Markogiannakis H, Toutouzas KG, Pararas NV, Romanos A, Theodorou D, Bramis I. Bilateral pneumothorax following endoscopic retrograde cholangiopancreatography: a case report. Endoscopy. 2007;39(Suppl 1):E195.

2. Ferrara F, Luigiano C, Billi P, Jovine E, Cinquantini F, D'Imperio N. Pneumothorax, pneumomediastinum, pneumoperitoneum, pneumoretroperitoneum, and subcutaneous emphysema after ERCP. Gastrointest Endosc. 2009;69(7):1398-1401.

3. Ciaccia D, Branch MS, Baillie J. Pneumomediastinum after endoscopic sphincterotomy. Am J Gastroenterol. 1995;90(3):475-477.

4. Guerra F, Giuliani G, Coletti M. Images in Emergency Medicine. Elderly female with abdominal pain. palpebral emphysema from endoscopic retrograde cholangiopancreatography-related retroperitoneal perforation. Ann Emerg Med. 2015;66(1):89, 95.

5. Cotton PB, Lehman G, Vennes J, Geenen JE, Russell RC, Meyers WC, Liguory C, et al. Endoscopic sphincterotomy complications and their management: an attempt at 
consensus. Gastrointest Endosc. 1991;37(3):383-393.

6. Enns R, Eloubeidi MA, Mergener K, Jowell PS, Branch MS, Pappas TM, Baillie J. ERCP-related perforations: risk factors and management. Endoscopy. 2002;34(4):293298.

7. Avgerinos DV, Llaguna OH, Lo AY, Voli J, Leitman IM. Management of endoscopic retrograde cholangiopancreatography: related duodenal perforations. Surg Endosc. 2009;23(4):833-838.

8. Loperfido S, Angelini G, Benedetti G, Chilovi F, Costan F, De Berardinis F, De Bernardin M, et al. Major early complications from diagnostic and therapeutic ERCP: a prospective multicenter study. Gastrointest Endosc. 1998;48(1):1-10.

9. Freeman ML, Nelson DB, Sherman S, Haber GB, Her- man ME, Dorsher PJ, Moore JP, et al. Complications of endoscopic biliary sphincterotomy. N Engl J Med. 1996;335(13):909-918.

10. Christensen M, Matzen P, Schulze S, Rosenberg J. Complications of ERCP: a prospective study. Gastrointest Endosc. 2004;60(5):721-731.

11. Machado NO. Management of duodenal perforation postendoscopic retrograde cholangiopancreatography. When and whom to operate and what factors determine the outcome? A review article. JOP. 2012;13(1):18-25.

12. Alfieri S, Rosa F, Cina C, Tortorelli AP, Tringali A, Perri V, Bellantone $\mathrm{C}$, et al. Management of duodeno-pancreatobiliary perforations after ERCP: outcomes from an Italian tertiary referral center. Surg Endosc. 2013;27(6):20052012. 